\title{
ENTREVISTA COM JOSÉ AMÉRICO MIRANDA
}

\section{HÉLIO DE SEIXAS GUIMARÃES}

Universidade de São Paulo

São Paulo, São Paulo, Brasil

Resumo: O professor José Américo Miranda trata nesta entrevista do trabalho que vem realizando nos últimos anos para o estabelecimento de texto e edição da poesia de Machado de Assis, indicando especificidades do tratamento dos textos desse gênero praticado pelo escritor desde a juventude até os anos finais de sua vida.

Palavras-chave: Machado de Assis; poesia; edição.

\section{INTERVIEW WITH JOSÉ AMÉRICO MIRANDA}

Abstract: In this interview, professor José Américo Miranda addresses his work in recent years for establishing the text and editing the poetry of Machado de Assis and points out unique aspects in treating texts of this genre, in which Machado engaged from his youth until the final years of his life.

Keywords: Machado de Assis; poetry; editing. 


\section{J} osé Américo Miranda, professor aposentado da Universidade Federal de Minas Gerais, tem se dedicado nos últimos anos ao estabelecimento de texto, publicação e edição de textos de Machado de Assis. Até o momento, editou, sempre com a participação de colaboradores, vários poemas: "O Progresso", "Gabriela da Cunha", "Saudades", "Lúcia", "O dilúvio", "Fé", "A Caridade", "A jovem cativa", "No limiar", "Aspiração", "Os arlequins", "Cleópatra", "As ondinas", "Maria Duplessis", "As rosas", "Os dous horizontes", "Monte Alverne", "As ventoinhas", "Alpujarra", "Versos a Corina - III (Fragmento)", "No álbum do Sr. F. G. Braga", Os deuses de casaca (poema dramático, ou teatro em versos), "Prelúdio", "Visão", "Menina e moça". Também editou os seguintes textos em prosa: "Abertura pelo $\mathrm{Sr}$. Machado de Assis, Presidente" (discurso na sessão inaugural da Academia Brasileira de Letras) e "O velho Senado", ambos em colaboração com Alex Sander Luiz Campos; e "A nova geração", com Gracinéa I. Oliveira.

Miranda também tem feito descobertas de textos praticamente desconhecidos, até mesmo da crítica especializada. É o caso de um texto crítico de Machado a respeito de Procelárias, de Magalhães de Azeredo, garimpado nas páginas do Jornal do Commercio, e apresentado em 2018 na seção "Páginas recolhidas" da Machado de Assis em linha, em colaboração com Alex Sander Campos. Ali, explicitava alguns dos seus critérios de edição:

Mantiveram-se as formas "dous" e "cousa". [...] As citações de versos (quer de poetas estrangeiros, quer da obra de Magalhães de Azeredo) foram transcritas em acordo com edições confiáveis, preparadas por especialistas ou pelo próprio autor, no caso de Azeredo; em rodapé registrou-se a lição presente no Jornal do Commercio. Foram elaboradas algumas notas ao texto, todas de nossa responsabilidade; informações presentes nessas notas, cujas fontes não estão nelas indicadas, foram obtidas em obras de consulta que constam das referências ao final do texto. (CAMPOS; MIRANDA, 2016)

Com o intuito de incentivar a edição fidedigna de textos do autor, criou em 2018, com a colaboração do professor Alex Sander Luiz Campos, a revista Machadiana Eletrônica (http://periodicos.ufes.br/machadiana), dedicada principalmente à divulgação de novas edições de obras de Machado de Assis e de estudos sobre essa questão.

$\mathrm{Na}$ entrevista que segue, realizada por correspondência eletrônica em janeiro de 2020, José Américo Miranda trata do estado atual da edição da 
poesia de Machado de Assis, discorre sobre alguns dilemas apresentados no embate com textos machadianos e explica as decisões que tomou ao editálos.

\section{Como e quando você editou um texto de Machado de Assis pela primeira vez? O que o levou a realizar esse trabalho?}

Comecei a estudar a poesia de Machado de Assis por volta do ano de 2010, ocasião em que fiz um pós-doutorado na USP, sob a supervisão do prof. Murilo Marcondes de Moura. Naquele ano, estudei o cânone da poesia machadiana, que é constituído pelos poemas que constam de suas Poesias completas, publicadas em 1901. Numa outra etapa, com bolsa DCR (Desenvolvimento Científico Regional) do CNPq e apoio da Fundação de Amparo à Pesquisa e Inovação do Espírito Santo (FAPES), estudei os poemas que o autor havia incluído em seus três primeiros livros de poesia Crisálidas, Falenas e Americanas - e, mais tarde, excluiu de sua obra, por ocasião da publicação das Poesias completas. Na convivência com a obra poética do autor, chamou-me a atenção a frequência de irregularidades e de diferenças entre as edições correntes de sua obra poética e os textos das fontes primárias. Por fim, passei a estudar as poesias que o autor jamais pusera em livros, deixara esparsas na imprensa do século XIX. Essa poesia foi reunida ao longo do século XX, e foi incluída em duas edições no início do século XXI - em Toda poesia (2008), organizada por Cláudio Murilo Leal, e em A poesia completa (2009), reunida por Rutzkaya Queiroz dos Reis.

O contato com a poesia dispersa de Machado de Assis foi decisivo para a tomada de decisão de editar sua obra poética. O exame atento dos textos revela que eles têm sido transmitidos da forma como foram transcritos das fontes primárias pelos pesquisadores que primeiro se deram a esse trabalho; os editores não voltaram às fontes primárias, e os erros eventualmente presentes na primeira transcrição (para publicação em livro) de cada poema se transmitiram a todas as edições subsequentes. Citarei apenas um exemplo (exemplar): o poema "Gabriela da Cunha", em versos alexandrinos, foi primeiro publicado no Correio Mercantil, em 29 de dezembro de 1861; depois, foi transcrito para livro em Vida e obra de Machado de Assis, 1981, por Raimundo Magalhães Júnior. Nessa transcrição há cerca de 10 erros (num poema de apenas 22 versos!); todos eles se transmitiram a todas as edições posteriores do poema (sinal claro de que nenhum dos editores retornou à 
fonte primária, para conferir o texto). Os erros incluem alterações da pontuação (frequentíssimas), alterações no emprego de iniciais maiúsculas, trocas de palavras (substituição de "olvido" por "ouvido"), inversão de palavras, omissão de palavra (alterando a medida do verso), alteração na disposição espacial dos versos. Conclusão: a tarefa mais urgente, por ora, é a do retorno às fontes primárias, para recuperação da forma correta dos poemas.

2. No embate direto com o texto de Machado, o que mudou ao longo do tempo? Há aspectos que você considerava importantes e hoje não considera mais; ou o contrário, há aspectos que via como desimportantes, aos quais atualmente dá mais atenção?

O que descobrimos a cada passo (incessantemente fazemos descobertas) é a confirmação da excelência admirável dos textos. O principal aspecto deles, a que eu não atribuía grande importância, é o da pontuação que Antônio Houaiss afirma ser bem próxima da usada atualmente (isso, entretanto, não é bem assim). Entendo que a pontuação do autor deve ser respeitada ao máximo; naquilo em que ela se afasta dos padrões atuais, não há obscurecimento do texto - que é sempre claro. A pontuação, muitas vezes, tem importante valor expressivo. Sempre que alguma intromissão for feita na pontuação do autor (às vezes isso é necessário), o leitor deve ser avisado em nota. Falhas tipográficas, como a ausência de ponto final num período, são frequentes (nesses casos, nem seria necessário o registro em nota de rodapé). A atualização ortográfica dos textos era feita, no início, sem maiores preocupações; hoje, reconheço que isso altera (ou pode alterar) a linha melódica dos versos, introduzindo nelas pequenas diferenças entre a pronúncia do tempo em que os poemas foram compostos e a atual. Apesar disso, continuo defendendo a atualização ortográfica - elas não alteram o sentido, e as perdas (mudanças) materialmente sensíveis na sonoridade não são grandes. Uma atitude conservadora, com relação à atualização ortográfica, interessa mais ao estudioso da língua do que ao leitor comum; essa é uma diferença importante entre as edições que tenho realizado e uma edição crítica.

4. Quais os principais dilemas e desafios que você, como editor de textos de Machado de Assis, enfrentou? 
Os desafios de um editor de textos de Machado de Assis relacionam-se aos nossos parcos conhecimentos filológicos e de história da língua (deficiência nossa) e à falta de uma tradição sólida de edição de textos no Brasil. A língua de Machado de Assis é erudita, de nível muito elevado - nada nos textos dele está ali por acaso, mesmo nos textos mais "despretensiosos"; partimos do princípio de que as poucas coisas "soltas", isto é, que não ficam claras para nós, que parecem não fazer nexo com o restante do texto, provavelmente parecem soltas por deficiência nossa. Isso nos lembra o "Lundu do escritor difícil", de Mário de Andrade - "Eu sou um escritor difícil, / Porém culpa de quem é!... / Todo difícil é fácil, / Abasta a gente saber." (ANDRADE, 1955) - e também a distinção entre dificuldade e hermetismo: a dificuldade é deficiência (ignorância) nossa (do leitor); se estudamos, alcançamos a compreensão dos textos, penetramos-lhes a significação; quanto ao hermetismo, não há ciência que o penetre. Machado de Assis não é um escritor hermético.

5. A seu ver, quais seriam os limites para a atualização do texto de Machado? Como você lida, por exemplo, com as diferenças entre os usos de Machado e as regras atuais? Se puder, por favor comente questões de pontuação, ortografia, uso de itálicos para estrangeirismos etc.

A preparação de uma edição, por um lado, deve respeitar o texto original tanto quanto for possível (respeito à forma ideada pelo autor; respeito à língua do tempo e do autor), e, por outro, deve torná-lo acessível ao leitor atual. Muitas referências de tempos passados se perdem, o mundo da cultura muda com o passar dos anos. A boa edição, na minha opinião, deve procurar equilíbrio entre as duas ideias: não deve "traduzir" o autor para o moderno (tirando-lhe suas peculiaridades), e não deve conservá-lo lá, como algo irredutível, que não se pode tocar (para isso, as edições fac-similares são excelentes). A chamada "atualização do texto" deve ser bem ponderada, tendo em vista o público alvo da edição.

Às vezes, eu gosto de me explicar por símiles, e os das artes plásticas são especialmente convenientes, porque apelam ao sentido da visão. As convicções se formam com mais facilidade quando as evidências são visíveis, entram pelos olhos. 
Imaginemos uma igreja com altares dourados, pinturas etc. $\mathrm{O}$ que sucede a essas obras com o tempo? Ficam desbotadas, empoeiradas afetadas pelo tempo, enfim. Quando se procede à restauração dessas obras, como elas ficam? Brilhantes, reluzentes, claras - supostamente como foram vistas logo depois de realizadas. A restauração, portanto, suprime (de algum modo) os efeitos do tempo (que decorreu entre a produção da obra e sua recepção atual).

Quando atualizamos a ortografia de um texto (onde ela é passível de atualização; nunca onde a atualização alteraria algo no plano da significação ou das relações entre elementos formais do texto), o que fazemos é "tirar-lhe a poeira do tempo", que se depositou sobre ele. Atualizadas, as palavras soam aos ouvidos e aos olhos de hoje com a naturalidade do hábito contemporâneo, como naquele tempo soavam naturais aos ouvidos e aos olhos acostumados àquelas sonoridades e àquela ortografia e àquela pontuação (cujos padrões se alteraram no decorrer do tempo). Nisso, as edições que fazemos distinguem-se nitidamente das edições críticas, porque muitas atualizações implicam diferenças entre a língua contemporânea nossa e a língua do tempo em que o texto foi criado - só diferenças muito pequenas são toleradas nas atualizações (como o grau de abertura de certas vogais e a omissão de consoantes que hoje são mudas).

Então, se concordarem com meus argumentos, talvez pudéssemos chamar de "edições restauradas" àquelas que costumamos fazer (por analogia com as restaurações de obras de artes plásticas).

Quanto ao uso de itálicos para marcar os estrangeirismos, entendo que eles são até mesmo educativos: há de o leitor saber que, na data em que aquele texto foi escrito, a palavra estrangeira empregada era de importação relativamente recente (não havia sido aportuguesada, incorporada ao léxico de nossa língua; ou pode mesmo ter tido seu uso abandonado - caso em que uma nota ao texto seria necessária, para esclarecimento do leitor). A marcação do estrangeirismo com itálico não obscurece o texto - deve, portanto, ser conservada.

6. No interior da obra de Machado, e às vezes no interior de um mesmo texto machadiano, há variações, tanto no uso da pontuação como na ortografia (cousa/coisa; devagar/de vagar; etc.) e na acentuação (no uso da crase, por exemplo). Como você lida com isso? Tende a uniformizar ou mantém essas variações? 
Variações na pontuação dos textos devem ser avaliadas; quando alguma pontuação é alterada, o leitor deve ser avisado em nota. A pontuação é o aspecto mais frequentemente alterado pelos editores. Essas variações podem decorrer da ação voluntária de tipógrafos ou de acidentes na tipografia, mas podem ser obra do próprio autor. Sempre que houver a possibilidade de o próprio autor ser o responsável pelas oscilações, elas devem ser respeitadas. A língua muda com o tempo - por necessidade dela; tanto a língua falada como a escrita. Essa necessidade pode resultar em certa forma de pontuação numa passagem, e outra forma em outra passagem de estrutura sintática semelhante. Isso é revelador do sentimento, da hesitação, do falante ou do escritor em relação à sua própria língua.

O mesmo fenômeno sucede na ortografia de certas palavras (como "cousa/coisa"; "devagar/de vagar") - o caso das palavras que eram escritas com separação das partes e hoje são escritas como uma só palavra é geralmente de fácil solução: a grafia numa só palavra não lhes altera o sentido nem a sonoridade (portanto, não há problemas no tocante à atualização gráfica). Desses casos, o que demanda mais atenção é a distinção entre "se não" e "senão", que sempre (ou quase sempre) vem grafada "se não". Tais grafias parecem refletir modos de percepção das significações, que se alteram com o tempo e com o uso.

Palavras grafadas com o ditongo "ou" ("cousa", "dous", "noute", por exemplo) parecem ser formas mais prestigiosas na escrita, no tempo de Machado de Assis; a pronúncia, tudo o indica, já era "oi". Faço só duas observações muito pontuais a respeito. Primeira observação: em "O velho Senado", publicado por Machado de Assis na Revista Brasileira, em 1898, todas as ocorrências da palavra "coisa" vinham assim grafadas, com uma única exceção: aparece a grafia "cousa" apenas numa passagem enfática ("Quanta cousa obsoleta!"). Editei esse texto em colaboração com o professor Alex Sander Luiz Campos. ${ }^{1}$ Quando o mesmo texto passou ao livro Páginas recolhidas (1899, com segunda edição em 1900), todas as ocorrências passaram à grafia "cousa". Isso pode ter sido obra ou cuidado do autor, pelo fato de a palavra com esta grafia ter mais prestígio na tradição literária do que aquela que já refletia a pronúncia do tempo - "coisa". Não se pode, entretanto, ter certeza de que essa explicação seja correta; pode ser questão do padrão adotado nas gráficas da editora de H. Garnier. Segunda observação: em Falenas, no poema "Uma ode de Anacreonte", no texto da

${ }^{1}$ Ver em: http://periodicos.ufes.br/almanaque/issue/view/744. 
pequena ode transcrita no "quadro" dramático em tradução para o português de Antônio Feliciano de Castilho, "dous" rima com "depois" - o que parece ser clara indicação da pronúncia daquele tempo (a escrita não indica necessariamente a pronúncia de uma palavra). $\mathrm{O}$ fato de "dous" aparecer no texto pode, talvez, receber as mesmas duas possíveis explicações feitas para a palavra "cousa" em "O velho Senado". O fato é que no livro A lírica de Anacreonte (Paris: Typographia de Ad. Lainé et J. Havard, 1866), tradução de Antônio Feliciano de Castilho, vem grafado "dois".

A sinalização da ocorrência de crase, no século XIX, era feita com o acento agudo, não com o acento grave, que utilizamos atualmente para isso. Nos textos de Machado de Assis, parece-me (é uma impressão apenas, já que não me dediquei ao estudo dessa questão específica), a sinalização da crase é bastante uniforme e bem próxima do uso atual - apenas com a diferença do sinal empregado para sinalizá-la. No século XIX, muitas vezes, o acento agudo aparecia sobre a preposição "a", sem que houvesse crase; nos textos de Machado de Assis com que lidei, não ocorre isso. Acento sobre o artigo "a", que é raro, muito provavelmente, pode ser atribuído à tipografia (erro) - não conheço ocorrência disso em textos de Machado de Assis.

7. Machado escreveu e publicou poemas durante mais de quatro décadas, período em que ajudou a definir, como escritor e como presidente da Academia, um novo padrão de escrita em língua portuguesa. Você identifica mudanças significativas entre o padrão da escrita dos poemas iniciais e o dos publicados já no século XX?

No campo da poesia, talvez a principal mudança ocorrida ao longo da vida do autor tenha sido o abandono do verso branco, muito empregado por ele (foi um mestre na arte desse verso tão difícil) até cerca de 1875-1880. O decassílabo (único verso que admitia a ausência de rima àquela altura da história de nossa poesia) foi o verso preferido de Machado de Assis - o mais praticado por ele nas suas Poesias completas.

$\mathrm{Na}$ poesia, como na prosa, Machado de Assis aprimorou-se com o tempo. Sua grande capacidade de pensamento, sua competência dialética, entretanto, e sua ironia podem ser identificadas em seus textos desde os primeiros anos. 
8. Como você lida com as epígrafes de textos em língua estrangeira? Mantém o modo como Machado transcreveu ou faz alterações para adequar a edições mais modernas e fidedignas do que aquelas utilizadas por Machado?

No tocante às epígrafes em línguas estrangeiras, assim como as grafias de nomes de autores estrangeiros (exemplo: era comum o emprego da forma "Shakspeare", para designar o poeta e dramaturgo inglês), sempre faço as alterações necessárias para adequá-las a edições e usos mais modernos e fidedignos - evidentemente com o devido registro em nota de rodapé da forma empregada pelo autor.

9. Como você lida com as notas explicativas? Para você, o que seria um bom ponto de equilíbrio no uso das notas?

Eu uso notas explicativas sempre que há algum aspecto do texto (linguístico, histórico, cultural, mitológico) que não é do conhecimento do leitor médio (evidentemente essa avaliação será sempre subjetiva...). Um bom equilíbrio no uso das notas pode ser alcançado, suponho, quando se identificam os pontos em que eu mesmo tive dificuldade de compreender o texto (a referência ou a alusão). Como José Paulo Paes, que, quando indagado por que ele traduzia textos, respondeu "traduzo porque não entendo o original" (citado de memória), posso dizer, adaptando as palavras ao ofício de editor: ponho notas onde não penetro por meus próprios meios, onde não compreendo o texto sem o recurso a pesquisas para esclarecimento da passagem.

10. No caso da poesia de Machado de Assis, o que ainda há a fazer em termos de estabelecimento de texto e edição?

A edição crítica das Poesias completas, publicada em 1976 pela editora Civilização Brasileira (com segunda edição em 1977), está longe de correta resultou da aplicação de critérios estabelecidos pela Comissão Machado de Assis, mas apresenta registro falho de variantes, poemas em que faltam versos (em "Uma ode de Anacreonte", por exemplo, faltam dois versos), e a 
descrição formal dos poemas, na introdução crítico-filológica, muitas vezes não corresponde à realidade textual. Em que pese todo o esforço dos pesquisadores, sem o trabalho dos quais a poesia de Machado de Assis estaria em situação ainda mais precária, a resposta a essa pergunta é a seguinte: tudo está por ser feito; falta estabelecer a forma correta dos poemas.

\section{Referências:}

ANDRADE, Mário de. "Lundu do escritor difícil". In: Poesias completas. São Paulo: Martins, 1955, p. 334-334.

CAMPOS, Alex Sander Luiz; MIRANDA, José Américo. Um texto crítico de Machado de Assis. Machado Assis em Linha, São Paulo , v. 9, n. 18, p. 146-157, ago.

2016 Disponível

em $<$ http://www.scielo.br/scielo.php?script=sci_arttext\&pid=S198368212016000200146\&lng=pt\&nrm=iso>. Acesso em 04 fev. 2020. doi:10.1590/1983-6821201691811.

HÉLIO DE SEIXAS GUIMARÃES é professor livre-docente na Universidade de São Paulo e pesquisador do CNPq; desenvolve atualmente o projeto de pesquisa "Efeitos da tradução sobre a recepção e a consagração de Machado de Assis" com Bolsa Produtividade PQ (nível 2). Dhttp://orcid.org/0000-0002-2054-2689. E-mail: hsg@usp.br 